\title{
Load-displacement behavior of glass fiber/epoxy composite plates with circular cut-outs subjected to compressive load
}

\begin{abstract}
An experimental study of the behavior of woven glass fiber/epoxy composite laminated panels under compression is presented. Compression tests were performed on to 16 fiberglass laminated plates with and without circular cut-outs using the compressed machine. The maximum load of failure for each of the glass-fiber/epoxy laminated plates under compression has been determined experimentally. A parametric study was performed as well to investigate the effects of varying the centrally located circular cut-out sizes and fiber angle-ply orientations on to the ultimate load. The experimental work revealed that as the cutout size increases, the maximum load of the composite plate decreases. Also, it has been observed that cross-ply laminates possess the greatest ultimate load as compared to other types of ply stacking sequences and orientations.
\end{abstract}

